\title{
Evaluation of Risk Management Practice in the Nigeria Construction Industry
}

\author{
Moses C. Ugwu' ${ }^{1}$, Temidayo O. Osunsanmi ${ }^{1}$, and Clinton O. Aigbavboa1 \\ ${ }^{1}$ SARCHhI in Sustainable Construction Management and Leadership in the Built Environment, \\ Faculty of Engineering and the Built Environment. University of Johannesburg, South Africa. \\ ${ }^{*}$ Corresponding author's e-mail:osunsanmidayo@gmail.com
}

\begin{abstract}
The construction industry is an essential contributor to a country's economic growth. Unfortunately, the sector's contribution to the economy is hindered by numerous risk surrounding a construction project. Despite the harmful effect of construction risk, it cannot be eliminated but it can only be managed. Therefore, this study aimed at evaluating the practice adopted for managing construction risk within Nigeria construction industry. The quantitative research approach was adopted, and a descriptive study was selected because it gives an accurate account of the characteristics, for example, the behaviour, opinions, abilities, beliefs and knowledge of a situation or group. The questionnaire was sent out to 200 respondents out of which a total of 150 questionnaires were valid. All the valid questionnaires were analysed using SPSS v23 adopting the exploratory factor analysis method. The findings showed that just like developed countries the Nigeria construction industry adopt the best practice of risk management in construction projects. These practices include risk identification, assessment, response and control. The exploratory factor analysis revealed that under risk identification the practice adopted by the construction professionals is dived into information sourcing and history of the project. Concerning risk assessment, the practice comprises of event analysis and creating a picture of the project. The method adopted for risk response includes generating a risk reduction methodology, establishing risk management back up plan and shifting the risk to a third party. Whereas for risk control the practice consists of enhancing construction project quality and improving the program plan of the construction project. The study contributes to the better management of construction project risk in Nigeria.
\end{abstract}

\section{KEYWORDS}

Risk management; Construction risk; Risk assessment; Risk control planning; Risk identification.

\section{INTRODUCTION}

One of the significant vital factors in a country's development is the construction industry. This is because the provision of infrastructures and amenities needed for the growth of the country cannot be established without the industry (Yimam, 2011). Despite the benefit of the industry, it is laden with risks when compared to other projects due to the very nature of the activities that are involved in construction projects (Dey, 2001). Fadun and Saka (2018), posited that a risk is an unforeseen event that prevents the completion of a construction project at the stipulated time and cost.

According to Mahamid, (2013), two significant factors have always attracted attention in the construction industry; these two are time and cost overruns hence projects completed with 
significant overruns has been linked to the construction industry (Abdul-Rhaman et al., 2015). Abderisak and Lindahl, (2015), reported that the initial budgets of many construction projects had been exceeded with an increase in the cost up to the range of $50-100 \%$ and sometimes beyond $100 \%$ in some cases. The inability to achieve the desired objectives of the construction projects is usually the aftermath of the occurrence of risks in construction works. Delays, cost overruns and a shortfall in quality are the most experienced adverse effects of risk in construction projects.

The main rationale behind construction risk management is not the total elimination of the risks that occur but having proper control over the whole risks (Dallas, 2006). Risk management in the Nigerian construction industry is still in the infancy phase which is unlike the developed countries (Odusamiet al., 2002). Harmonising the thoughts of Odeyinkaet al., 2007), the Nigerian construction industry is known for cost overruns, subsequent delays and project abandonment. Consequently, this study seeks to appraise the present level of risk management practice in Nigeria. The findings of Odusamiet al., (2002) \& Fadun and Saka (2018) also suggest that it is expedient to assess the factors responsible for the present state of risk management practice in the Nigerian construction industry. Therefore this study aims to evaluate the practice adopted for managing risk in the Nigeria construction industry.

\section{CONSTRUCTION RISK MANAGEMENT IN NIGERIA}

It has been reported in previous researches that industries that patronise construction services periodically do not practice risk management in projects and this has affected the project performance negatively (Aibinu and Jagboro, 2002). According to Ojo (2010) and Adeleke et al. (2018) who carried out research on entitlements and contract quarrels in a host of construction projects stated that the consequence of risks occurrence that was not appropriately assessed or incorporated by either customer, contractors and consultants as one of the leading causes of claims and disputes in the construction projects. According to Belel and Mahmood, (2012), who assessed risk management in the Nigerian construction industry, they identified knowledge deficiency as the most intolerant issue that hinders risk management practice as well as small experienced staffs as the primary source of risk in construction activities. They posited that the significant benefit of risk management is its contribution to project success. They opined that a large number of their respondents are conscious of managing risk with regards to safety threat on site compared to identifying the concept with relations to accomplishing the objectives of the project concerning cost, quality and time. They proposed that the workforce in the country's construction industry should be trained on how to manage risks (Belel and Mahmood, 2012).

Previous research results in Nigeria have established that organisations that employ construction services on a periodic basis do not analytically practice risk management, which has led to adverse effects for the performance of projects, for example, total abandonment of project (Aibinu and Jagboro, 2002). Also, a study conducted by Ojo, (2010), on claims and contract conflicts in numerous construction projects, had shown that the effect of risks occurrence that was not well assessed or incorporated by clients, contractors and consultants is a major cause of claims and disputes in construction projects. The country has failed to focus more on risk management during construction and the inability to manage risks properly consequently led to an increase in project failure (Nnadi et al. 2018).

\section{RISK MANAGEMENT PROCESS}


The process of managing risk is the bedrock that is attached to understanding as well as managing risks in project work. An efficient implementation of the process in a project requires the participation of all the steps in the process of risk management when dealing with risks. The risk management process consists of the main stages (Giannakis and Louis, 2011; Ubaniet al., 2015 \& Kuria and Kimutai 2018).

\section{Risk Identification}

This is the primary phase in the process of managing risk, and it has to do with capturing all the risks that tend occurring in the course of the project (Nnadi et al., 2018). This first stage lays the foundation for the succeeding steps of risk assessment and control as it is an eye-opener for organisations to understand inherent risk areas. When risk identification is done accurately, it guarantees effective managing of risk as it exposes hidden sources of losses that could escalate into incidences that could not be managed with unforeseen consequences (Ghasemi, et al. 2018). The outcome of not being able to identify positive risks is equal to the consequences of not identifying adverse risks (Fadun and Saka 2018).

\section{Risk Assessment/Analysis}

According to Kumar et al., (2018), assessing the identified risk is the following phase in the processes of managing risk after identification. Risk assessment is a process in which usable information is used in the determination of the frequency of occurrence as well as the degree of consequences in risk management (Olamiwale, 2014). Having identified all the risks in a project, the next thing to embark on is qualitative risk assessment which calls for additional analysis via investigating and estimation of the tendency of risk occurrence and its effect on each of the identified risk (Nnadi et al., 2018). The different factors that require consideration at this stage include the impact of risk on the objectives of a project and how it can be managed. Others are the timing of an occurrence, the probability of an event as well as its connection with other risks. Altogether, they give a proper understanding of each risk and facilitate a better response to each threat.

\section{Risk Responses}

The central component of the risk management process which determines whether any action will be taken with respect to the risks analysed in the course of identification, qualification and quantification stages is referred to as risk response (Ghasemi et al., 2018). Risk responses are arrived at by suggesting many options for the eradication or moderation of an anticipated risk and allocate the best substitute as a response (Nnadi et al., 2018). Olmiwale (2014), argued that risk response is the procedure of discovering or fashioning out alternative reactions to risk and the determination of activities for handling the risk, focusing opportunities and reducing pressures to achieving the objectives of the project. Thus, it has to do with choosing an appropriate policy to reduce the negative effect of a risk.

\section{Risk Control}

Necessary actions must be taken after risk identification, assessment and risk responses have been fully developed. Execution of risk plan is a part of risk supervision and control which should be a fundamental part of the project. The first out of the two main challenges encountered in the course of monitoring and controlling is the implementation of the risk plans as well as their effectiveness. The second main challenge is the designing of significant documentation to back up the process. 
Risks are being managed in such a manner to facilitate the effective management of the project. It is centred on a proactive approach other than a reactive approach to ensure the right measures are in place as well as continually refining them.

\section{METHODOLOGY}

This study was carried out in 3 cities in Nigeria; these cities are known to be the centre of construction development. These cities are Lagos, known as the commercial hub of the country, which has and is presently experiencing major construction projects; Port-Harcourt, a major city in the Niger-Delta region, known for its massive development due to the concentration oil companies; and lastly, the Federal Capital Territory (Abuja), this is the power seat of the country, and hence, it is expected to have lots of construction going on in this area. This forms the basis for the selection of the research area.

The choice of research approach is basically based on the nature of the research problems, objectives and questions. The quantitative survey method was adopted because a large portion of the sample population in the selected research area could be adequately covered in a relatively short period. This approach further makes use of standard research design and established procedures which make it possible to be replicated (Asika 2004). Also, a descriptive study was adopted because it gives a precise explanation of the features, for example, the conduct, sentiments, abilities, feelings and cognition of a situation or group.

The target population for this research comprised of active construction professionals located in Lagos, Port-Harcourt and Abuja FCT. These include managing directors, construction project managers and construction managers (Site supervisors) in the three (3) cities mentioned above. A total of two hundred (200) questionnaires were sent out, and only one hundred and fifty (150) was retrieved and used for the analysis. The data generated through the questionnaire was analysed using SPSS v23.

\section{FINDINGS, ANALYSIS AND DISCUSSION}

According to Adeleke et al., (2018), there are four significant steps in the risk management practice they include; risk identification, analysis, response and control. These practices were analysed one after the order to determine the major form of risk management practice utilised in each step. The study adopted principal component analysis to examine the level at which the construction industry of Nigeria follows the risk management best practices of identification, assessment/analysis, responses and control. The table presents the KMO and Barlett'S test of all the four practices. A cursory look at the table shows that the KMO yields a value of above 0.5 for all the four practices which confirm that the data is fit for factor analysis.

Table 1. KMO and Bartlett'sTest of Sphericity for Risk management practice

\begin{tabular}{|c|c|c|c|c|}
\hline & Identification & Assessment & Response & Control \\
\hline $\begin{array}{l}\text { Kaiser-Meyer-Olkin measure of } \\
\text { sampling adequacy. }\end{array}$ & 0.755 & 0.841 & 0.663 & 0.718 \\
\hline Bartlett's test Approx. chi-square & 2008,134 & 20022,245 & 1984,327 & 2115.612 \\
\hline of sphericity & .240 & .251 & .197 & .214 \\
\hline Sig. & .000 & .000 & .000 & .000 \\
\hline
\end{tabular}


The study adopted direct oblimin method for rotating the components that make up the four risk management practices. Due to space consideration the scree plot, communalities and variance table were not included. Also, some none essential components within the pattern matrix tables were also excluded.

Table 2. Pattern matrix for risk identification

\begin{tabular}{lll} 
& \multicolumn{2}{c}{ Factor } \\
\hline C.3 Brainstorming & 1 & 2 \\
C.4 Delphi techniques & $\mathbf{. 3 0 9}$ & .081 \\
C.2 Interview or expert opinion & $\mathbf{. 2 3 2}$ & .022 \\
C.5 Checklist & $\mathbf{. 1 6 7}$ & .068 \\
C.1 Past experience & .084 & $\mathbf{. 6 5 6}$ \\
\hline
\end{tabular}

Table 2 presents the pattern matrix for risk identification. The table shows that they are two significant factors for risk identification. However, three items loaded onto Factor 1. the items are; 'brainstorming'; 'Delphi techniques' and 'interview or expert opinion'. These set of factors forms the tools that could be used to identify risk and hence know how to manage it in the Nigerian construction industry. The possession of these factors is important in identifying risks associated with the construction industry in Nigeria. Thus, they have marked 'Information sourcing'. With a variance of $42.020 \%$ of the total variance.

Whereas, a total of two items loaded onto Factor 2. This factor loads 'past experience' and 'checklist'. These factors were labelled 'History'. With a variance of $23.560 \%$ of the total variance, these factors are principal but were ranked low in respect to other factors that support the identification of risk as a method of risk management in the construction industry in Nigeria. The findings from this study coincides with the work done by (Adeleke et al.,2018).

Table 3. Pattern matrix for risk assessment

\begin{tabular}{lll} 
& \multicolumn{2}{c}{ Factor } \\
\hline D.4 Sensitivity analysis & 1 & 2 \\
D.3 Scenario analysis & $\mathbf{. 2 9 1}$ & .091 \\
D.5 Probabilistic analysis & $\mathbf{. 2 5 3}$ & .071 \\
D.2 Decision trees & $\mathbf{. 1 4 1}$ & .053 \\
D.1 Risk priority number & .091 & $\mathbf{. 7 0 3}$ \\
\hline
\end{tabular}

Table 3 shows that three items loaded onto Factor 1. This factor loads 'sensitivity analyses; 'scenario analysis' and 'probabilistic analysis'. Thus, they have marked 'Event analysis'. With a variance of $40.160 \%$ of the total variance, these factors were identified as the most important for risk assessment in the construction industry in Nigeria. A total of two items loaded onto Factor 2. From table 3, these two items related to risk factors that that should have the maximum attention. This factor loads 'decision tree' and 'risk priority number (RPN)'. These factors were labelled 'Pictorial risk assessment'. With a variance of $21.060 \%$ of the total variance.

Table 4. Pattern matrix for risk response 


\begin{tabular}{llcr}
\hline & \multicolumn{3}{c}{ Factor } \\
\hline E.1 Risk mitigation/reduction & 1 & 2 & 3 \\
E.4 Risk avoidance & $\mathbf{. 2 1 7}$ & .111 & .024 \\
E.3 Risk acceptance & $\mathbf{. 2 0 4}$ & .104 & -.218 \\
E.8 Risk exploit & $\mathbf{. 1 3 6}$ & .002 & -.057 \\
E.2 Contingency plan & .091 & $\mathbf{. 7 0 3}$ & -.014 \\
E.5 Risk transfer & .072 & $\mathbf{. 6 6 1}$ & .199 \\
E.6 Risk share & .100 & .122 & $\mathbf{. 6 0 0}$ \\
E.7 Risk enhance & -.184 & .131 & $\mathbf{. 5 5 4}$ \\
& -.034 & -.017 & $\mathbf{. 4 2 6}$ \\
\hline
\end{tabular}

The pattern matrix for risk response is presented in table 4. The first factor loads 'risk mitigation/reduction; 'risk avoidance' and 'risk acceptance'. These set of factors forms the tools that could be used to plan how construction professionals respond to risk and know how to manage it in the Nigerian construction industry. Thus, they were marked 'Risk reduction. A total of two items loaded onto Factor 2. This factor loads 'contingency plan' and 'risk exploit'. These factors were labelled 'Risk management backup plan'. With a variance of $25.387 \%$ of the total variance. Factor 3 loads a total of three items which are 'risk transfer', 'risk share' and 'risk enhance'. These factors can be labelled 'Risk management by a third party". With a variance of $11.237 \%$, these factors are ranked as the lowest that could help in risk response planning. The findings corroborates with the work done by (Belel and Mahmood, 2012).

Table 5. Pattern matrix for risk control

F.1 Submission of low estimates is avoided
F.4 Lack of consistency between BoI, drawings and specifications is identified and prevented

F.7 Gaps between implementation and specifications due to misunderstanding of drawings and specifications is identified and prevented

F.6 Non-conformance to quality is avoided

F.2 Undefined scope of work Factor

F.3 Inaccurate project programme is avoided .446 .158

F.5 Accidents are prevented because poor safety procedures are identified and .581 .176 addressed

Four items were loaded onto Factor 1. This factor loads 'submission of low estimates is avoided; 'Lack of consistency between bill of quantities, drawings and specifications are identified and prevented', 'Gaps between implementation and specifications due to a misunderstanding of drawings and specifications is identified and prevented' and 'Non-conformance to quality is avoided'. Thus, they were marked 'Construction project quality'. A total of three items loaded onto Factor 2. This factor loads 'undefined scope of work is prevented', 'inaccurate project programme is avoided' and 'Accidents are prevented because poor safety procedures are identified and addressed'. These factors were labelled 'Project programme. 


\section{CONCLUSION}

The construction industry in Nigeria is an essential driver of the country's economy. It drives the economy by contributing to the country's GDP, the provision of various infrastructure needed for the growth of the economy. Unfortunately, the growth of the construction industry is hindered by numerous risk surrounding a construction project. Despite the harmful effect of construction risk, it cannot be totally eliminated, but it can only be managed. Therefore, this study aimed at evaluating the practice adopted for managing construction risk within the Nigeria construction industry.

The reviewed from past literature as shown that risk can only be managed through following four steps which are; identification, assessment, response and control. Therefore, this study adopted principal component analysis to reveal the practice utilised for managing risk in all four steps.

The study revealed that under risk identification the practice adopted by the construction professionals is dived into information sourcing and history of the project. Concerning risk assessment, the practice is also divided into event analysis and creating a picture of risk assessment. The practice adopted for risk response includes generating a risk reduction methodology, establishing risk management back up plan and shifting the risk to a third party. Whereas for risk control the practice consists of enhancing construction project quality and improving the program plan of the construction project.

The study contributes towards the better management of risk within construction project in Nigeria and also improving the delivery of construction project within the country. The study recommends that construction stakeholders should embrace a rigorous process for managing risk with the intention of improving the overall quality of construction projects.

\section{ACKNOWLEDGEMENTS}

We acknowledge the department of construction management and quantity surveying University of Johannesburg.

\section{REFERENCES}

Asika, N. (2004). Research methodology: A process approach. Mukugamu \& Enterprises.

Abderisak, A. and Lindahl, G. (2015). Take a chance on me? Constructionclients' perspectives on risk management, ProcediaEconomics and Finance, 21: 548 - 554.

Abdul-Rahman, H., Wang, C. and Mohamad, F. S. (2015). Implementation of Risk Management in Malaysian Construction Industry: Case Studies. Journal of Construction Engineering

Adeleke, A. Q., Bahaudin, A. Y., Kamaruddeen, A. M., Bamgbade, J. A., Salimon, M. G., Khan, M. W. A., \& Sorooshian, S. (2018). The influence of organizational external factors on construction risk management among Nigerian construction companies. Safety and Health at Work, 9(1), 115-124.

Aibinu, A.and Jagboro, G. (2002). The effects of construction delays on project delivery in Nigerian construction industry. International journal of project management, 20(8): 593599.

Belel, Z. and Mahmood, H. (2012). Risk Management Practices in the Nigerian Construction Industry- A Case Study of Yola. Journal of Engineering Sciences, 7(3): 1-6.

Dey, P. K. (2001). Decision support system for risk management: a case study. Management Decision, 39(8): 634-649. 
Dindar, S., Kaewunruen, S., \& An, M. (2018). Identification of appropriate risk analysis techniques for railway turnout systems. Journal of Risk Research, 21(8), 974-995.

Fadun, O. S., \& Saka, S. T. (2018). Risk management in the construction industry: Analysis of critical success factors (CSFS) of construction projects in Nigeria. International Journal of Development and Management Review, 13(1).

Ghasemi, F., Sari, M. H. M., Yousefi, V., Falsafi, R., \& Tamošaitienė, J. (2018). Project Portfolio Risk Identification and Analysis, Considering Project Risk Interactions and Using Bayesian Networks. Sustainability, 10(5), 1609.

Giannakis, M. and Louis, M. (2011). A Multi-agent based frame work for supply chain risk management, Journal of Purchasing and Supply Management, (17): 23-31

Kuria, E. W., \& Kimutai, G. (2018). Internal organization environment and project performance in construction firms within nairobi city county, kenya. International Journal of Project Management, 3(1), 1-13.

Kumar, L., Jindal, A., \& Velaga, N. R. (2018). Financial risk assessment and modelling of PPP based Indian highway infrastructure projects. Transport Policy, 62, 2-11.

Mahamid, I. (2013). Effects of projects physical characteristics on costdeviation in road construction, Journal of King Saud University Engineering Sciences, 25 (1): 81-88.

Nnadi, E. O. E., Enebe, E. C., \& Ugwu, O. O. (2018). Evaluating the Awareness Level of Risk Management amongst Construction Stakeholders in Nigeria. International Journal of Construction Engineering and Management, 7(1), 47-52.

Odeyinka, H. A. (2000). An Evaluation of the Use of Insurance in the Managing Construction Risks. Construction Management and Economics, 18: 519-524.

Odeyinka, H. A., Oladapo, A. A. and Dada, J. O. (2007). An Assessment of Risk in Construction in the Nigerian Construction Industry. International Symposium on Globalisation and Construction, Construction in Developing Economies, 107: 359-368.

Odusami, K. T., Iyagba, R.R.O. and Omirin, M.M. (2002). The relationship between project leadership, team composition and construction project performance in Nigeria. International Journal of Project Management (21): 519 - 527.

Ojo, A. S. and Ogunsemi, D. R. (2009). Assessment of contractorsunderstanding of risk management in Seychelles constructionindustry, in Proceeding of the RICS COBRA Research

Olamiwale, I.O. (2014). Evaluation of Risk Management Practices in the Construction Industry in Swaziland. Master of Quantity Surveying Thesis, Tshwane University of Technology, Pretoria, South Africa.

Ubani, C. E., Amade, B., Okorocha, A. K., Agwu, A. and Okogbuo, F. (2015). Project Risk Management Issues in the Nigerian Construction Industry, International Journal of Engineering and Technical Research, 3(1): 217-232.

Yimam, A. H. (2011). Project management maturity in the construction industry of developing countries (the case of Ethiopian contractors) [Ph.D. thesis], University of Maryland, College Park, Md,USA. 